\begin{tabular}{|c|ccc|c|}
\hline & PORT SAID ENGINEERING RESEARCH JOURNAL
\end{tabular}

\title{
Simulation and Optimization Study of Ultra-Precision Turning Process
}

\author{
Elsanabary S. ${ }^{1}$, Elkaseer A. ${ }^{2}$, Abd-Rabbo S. $^{3}$, AbdElsalam M. ${ }^{4}$, Abdou $S^{5}$
}

\begin{abstract}
This paper presents a simulation and optimization study of the surface generation process in ultra-precision turning using a formerly proposed model by the authors in preceding work. However, the surface generation model was improved by incorporating the effect of cutting speed into the model considerations. Then, a series of simulation trials were undertaken to predict the generated surface roughness over a wide range of cutting conditions. Particularly, two different dual-phase materials, Brass 6040 and medium carbon steel AISI 1045 were examined under ranges of cutting speeds, feed rates in addition to varying geometries of cutting tools. The study was accomplished by conducting an optimization of the process aiming at identifying the optimal cutting conditions for the best possible performance of the process in terms of minimum roughness average $\left(\mathrm{R}_{\mathrm{a}}\right)$. In particular, two optimization techniques, Sequential Quadratic Programing (SQP) and Genetic Algorithm (GA), were utilized to tackle the enhanced model. The results demonstrated that although cutting speed influenced the process, cutting edge radius was the dominate parameter and feed rate was found to be the second most effective variable. Also, optimization results confirmed the superiority of the GA technique over SQP method to obtain the optimal cutting conditions for minimum roughness.
\end{abstract}

KEYWORD: Simulation, Optimization, Ultra-precision Turning, Surface Roughness Generation, Sequential Quadratic Programming, Genetic Algorithm

\section{INTRODUCTION}

Simulation of the machining process has received a great deal of interests by many researchers over the recent decades. Especially, a number of reasons were reported to address the needs for simulation, particularly to reduce the product cost, improve the final design, optimize the cutting conditions and minimize the production time [1]. In this case, simulation is a practice of the proposed model, which has to be validated initially, in order to find the optimum solutions [2]. After simulation, optimization of cutting conditions is an essential phase to maximize the benefits of the proposed model. The nature of optimization is to find the optimum of variables to evaluate either maximum or minimum solution [3].

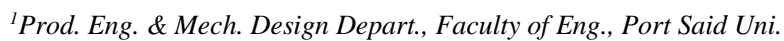
Email: samarelsanabary@yahoo.com

${ }^{2}$ Lecturer in Production Eng., Faculty of Eng., Port Said University. Email: elkaseeram@gmail.com

${ }^{3}$ Prof. of Production Eng., Faculty of Eng., Shoubra, Benha University. Email: saberabdrabbo@yahoo.com

${ }^{4}$ Prof. of Production Eng., Faculty of Eng., Ain Shams University. Email: msalam200042@yahoo.com

${ }_{5}^{5}$ Prof. of Production Technology, Faculty of Eng., Port Said University. Email:smiabdou@hotmail.com
As a result, optimization is rightly claimed to be the most significant contribution distinguishing the modern approach in the field of industrial machinery research [1]. Mathematical models can act as fitness functions and they can be optimized to obtain the best results for a process.

One example is optimizing the surface roughness during ultra-precision operation. The aim of optimization technique is to provide optimal or near-optimal solution(s) to the overall optimization problem formulated. A large number of techniques has been developed by researchers to solve optimization problems, and may be classified as conventional and non-conventional optimization techniques. One of the methodologies of the minimization functions used in Matlab is fmincon. This function is a reliable tool to solve the minimum of a constrained nonlinear objective function of several variables starting at user specified initial estimate. Particularly, fmincon uses (SQP) method with the active set optimization algorithm and contains a collection of algorithms that govern how a local minimum point is reached. The algorithms are Active-set (AS), (SQP), and Interior-point (IP). Also, fmincon provides to solve functions linear or nonlinear, constrained or unconstrained problems $[4,5]$. Another non-conventional optimization technique is Genetic Algorithm (GA). The (GA) starts with a randomly generated population of individuals, each one made by strings (or a chromosome) of the design variables, representing a set of points spanning the search space. The primary solution of the chromosome is evaluated by its 
fitness function, with respect to the objective function of the optimization problem. A set of chromosomes is called population and each of them at a given time is called generation. Each population size remains constant from one generation to another one. The basic mechanisms of GA are crossover and mutation. Crossover is the operation for exchange two chromosomes to a new off spring. This criteria is important because its assessment of the entire search space. The other characteristic, mutation, is a random modification of the chromosome in order to produce a new one and prevent the important information in the new chromosome. Finally, after a number of iterations of GA, the optimal solution obtained $[6,7$, and 8].

The motivation for this paper was to improve a previously developed model of ultra-precision turning by extending the considered parameters [12]. In particular, the influence of cutting speed on the minimum chip thickness was examined besides the effect of feed, tool geometries and elastic recovery on the resultant surface. By such improvement, the study aims to accurately simulate the surface generation process with the overall intend to optimize the machining process. Simulations have been performed on two workpiece materials, especially dualphase materials, and under variation of cutting conditions. In addition, two optimization techniques have been utilized that practice the proposed surface generation model. This paper begins by reviewing some of the most related work to simulation of micro-machining research area. The next section presents the experimental work carried out to consider the effect of cutting speed on the minimum chip thickness. Consequently, the simulation study of roughness generated for Brass 6040 and AISI 1045 steel under a wide range of cutting conditions using the pre-developed model is discussed. After that, the optimization of the ultraprecision turning process is given. Finally, conclusion is given in the last section.

\section{RELATED WORK}

Many researchers have studied the micro-cutting operations experimentally and theoretically in order to assess the process behavior [1-11]. The goal of these studies was to identify and control the dominating parameters for the best possible performance of the process. However, most of the reported work is related to the simulation of micro-end milling, and only few attempts were conducted to address the turning process.

Liu et. al. [2] implemented a simulation study for machining of different materials under different cutting conditions using the developed model of normalized minimum chip thickness. The authors conducted simulation trails on machining AISI 1040, AISI 1018 and Al6082-T6 materials over a wide range of cutting speed and edge radii varied from 0.5 to $5 \mu \mathrm{m}$. It was concluded that, for carbon steels there were proportional relationships between normalize minimum chip thickness and the cutting speed and cutting tool edge radius. This was mainly referred to the effect of thermal softening over the strain hardening for carbon steel. Moreover, the amount of carbon content is proportional to the normalized minimum chip thickness as shown in Fig. (1). On the other hand, for Al6082-T6 aluminum, the authors found that both cutting speed and tool edge radius had no effect on the normalized minimum chip thickness as shown in Fig. (2), this indicated that both the thermal softening and strain hardening effects demolished each other.

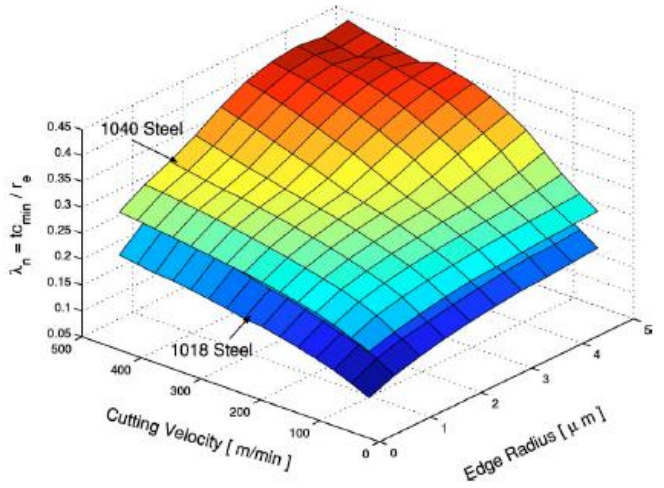

Fig (1): Normalized minimum chip thickness forAISI1018 steel and AISI1040 steel [2]

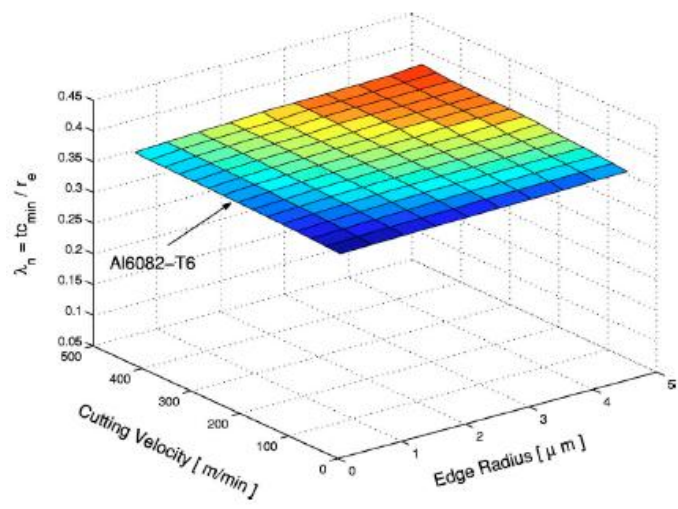

Fig.(2): Normalized minimum chip thickness for Al6082-T6 aluminum[2]

Liu et. al. [9] carried out a series of simulation study on micro-end milling to examine the effect of cutting tool geometry and process kinematics side by side to the process dynamics on generated surface roughness. The authors concluded that deterministic floor surface roughness was affected by feed rate. In addition, large edge radius produced higher surface roughness for both floor and side wall surfaces due to the increase in ploughing mechanism. Also, the authors reported the positive effect of vibrations that reduce the 3D surface roughness of floor surface at feed rate below the minimum chip thickness and increased the total 3D surface roughness at high feed rates. Finally, the authors recommended that to achieve a small surface roughness; the feed rate has to be equal (1:1.5) times of the minimum chip thickness. 
Tao [1] proposed a three-dimensional finite element method for modelling and simulation of the micro milling process, especially for tool geometry effects on micro milling performance. The author conducted experimental trials to validate the micro-milling performance using coated and uncoated micro end mill tools for micro slot of AISI 1045 steel. It was reported that feed rate had the most influence, followed by axial depth of cut, and cutting speed had less impact. At low uncut chip thickness, the coating thickness and coating frictions affected the cutting forces and tool temperatures. On the other hand, at high uncut chip thickness, the reduction of chip loads and tool temperatures was affected by coating friction and coating thickness, respectively. Finally, the author found that micro machinability was affected by the cutting mechanism and mechanics.

Özel et. al. [10] proposed a FE-simulation study of micro-milling in order to predict the chip formation, forces, strain, and temperature fields. The authors conducted experimental trials to validate the micro-milling model taken into account the dynamic force measurements in order to understand the effect of both feed rate and spindle speed on surface generation. The materials used in the experimental study were Al 2024-T6 aluminum and AISI 4340 steel, under cutting velocity ranging from 120 to $360 \mathrm{~m} / \mathrm{min}$ and edge radii varying from 1 to $5 \mu \mathrm{m}$. Also, The study enabled estimating the relations between the minimum chip thickness and edge radius, particularly in average of (42 to 45) \% for Al 2024-T6 aluminum and (30 to 36$) \%$ for AISI 4340 steel.

Tamang et. al. [11] developed a modeling and optimization study of turning a reinforced metal matrix composite. The material used in the experimental study was aluminum alloy with silicon carbide particle $(\mathrm{Al} / \mathrm{SiCp})$ and the cutting tool was a titanium nitride (TiN) coated carbide tool. The authors tried to evaluate the optimum roughness and tool wear by utilizing two different models; Response Surface Methodology (RMS) and Artificial Neural Network (ANN). Genetic algorithm (GA) was used to identify the optimum cutting parameters. The authors concluded that, the prediction error of roughness and tool wear were $4.98 \%$ and $3.82 \%$, respectively.

\section{EXPERIMENTAL SETUP}

In order to examine the effect of cutting speed on minimum chip thickness, a CNC center-lathe machine, BINNS \& BERRY, was utilized to cut longitudinal turning passes using new single carbide insert TCGT16T30X by KORLOY Inc. The cutters selected for this experimental study had the following geometric parameters, cutting nose radii $\left(r_{c}\right)$ were $200 \mu \mathrm{m}$ and $400 \mu \mathrm{m}$, and the end cutting edge radii $\left(r_{e}\right)$ in the range of $5 \mu \mathrm{m}$. The experiments were performed on variety of cutting speeds and feed rates to identify the optimal parameters at which minimum roughness occurred. In order to measure the average surface roughness ( $\mathrm{Ra}$ ) of machined samples, Surtronic 3

profilometer was used with cutoff length of $0.8 \mathrm{~mm}$. The final reading of ( $\mathrm{Ra})$ is the average of the seven measurements.

The cutting parameters applied during the experiments are presented in Table 1. The experiments covered the range of feeds from 5 to $15 \mu \mathrm{m} /$ revolution with a constant increment of $2.5 \mu \mathrm{m}$. Also, cutting speed varied from $50 \mathrm{~m} / \mathrm{min}$ to $150 \mathrm{~m} / \mathrm{min}$ with one level of axial depth of cut, $50 \mu \mathrm{m}$, applied to minimize the workpiece/cutter engagement and thus to keep cutting zone in the vicinity of the nose of the tool.

\section{Table 1: Cutting conditions}

\section{Depth of cut $(\mu \mathrm{m})$}

Cutting speed (m/min)

Feed $(\mu \mathrm{m} /$ revolution $)$

A single machining pass was performed to characterize the relationship between obtainable roughness and applied feed at different cutting speeds as shown in Figs. (3-a) and (3-b). For Brass 6040, as shown in Fig. (3-a), the minimum roughness was obtained at feed rates of $10,7.5$, 5,10 , and $7.5 \mu \mathrm{m} /$ revolution and for cutting speeds of 50 , $75,100,125$, and $150 \mathrm{~m} / \mathrm{min}$, respectively. However, the minimum roughness for AISI 1045 steel as shown in Fig (3-b) was obtained at feed rates of 12.5, 10, 10, 7.5 and 7.5 $\mu \mathrm{m} /$ revolution for cutting speeds of $50,75,100,125$, and $150 \mathrm{~m} / \mathrm{min}$, respectively.

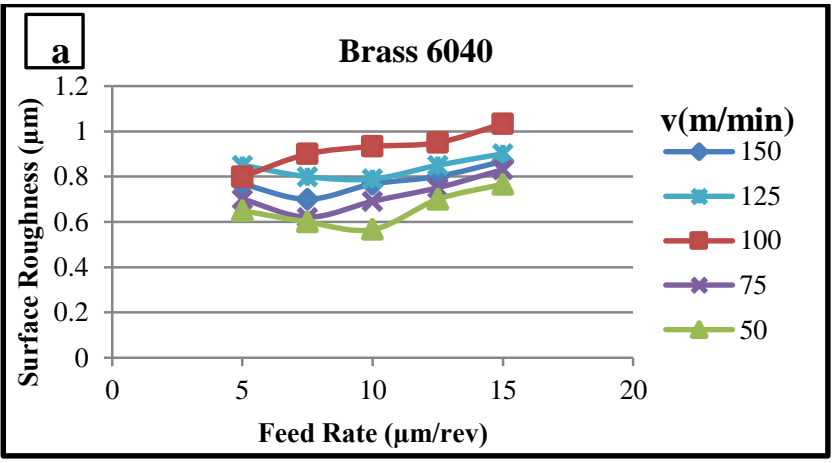




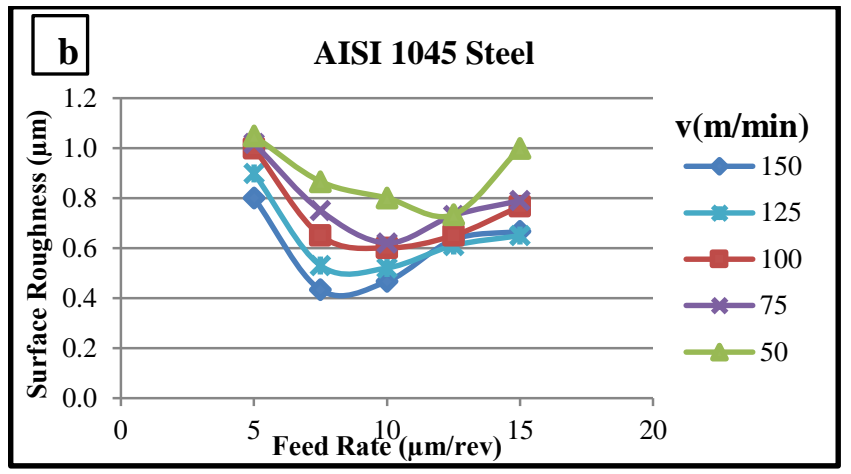

Fig. (3): Surface roughness vs. feed rate at different cutting speeds for (a) Brass 6040 and

(b) AISI 1045 steel

Accordingly, regression analysis was established to estimate the relationship between the minimum chip thickness and cutting speed taken into account the minimum roughness occurred for Brass 6040 and AISI 1045 steel as shown in Figs.(4-a) and (4-b).
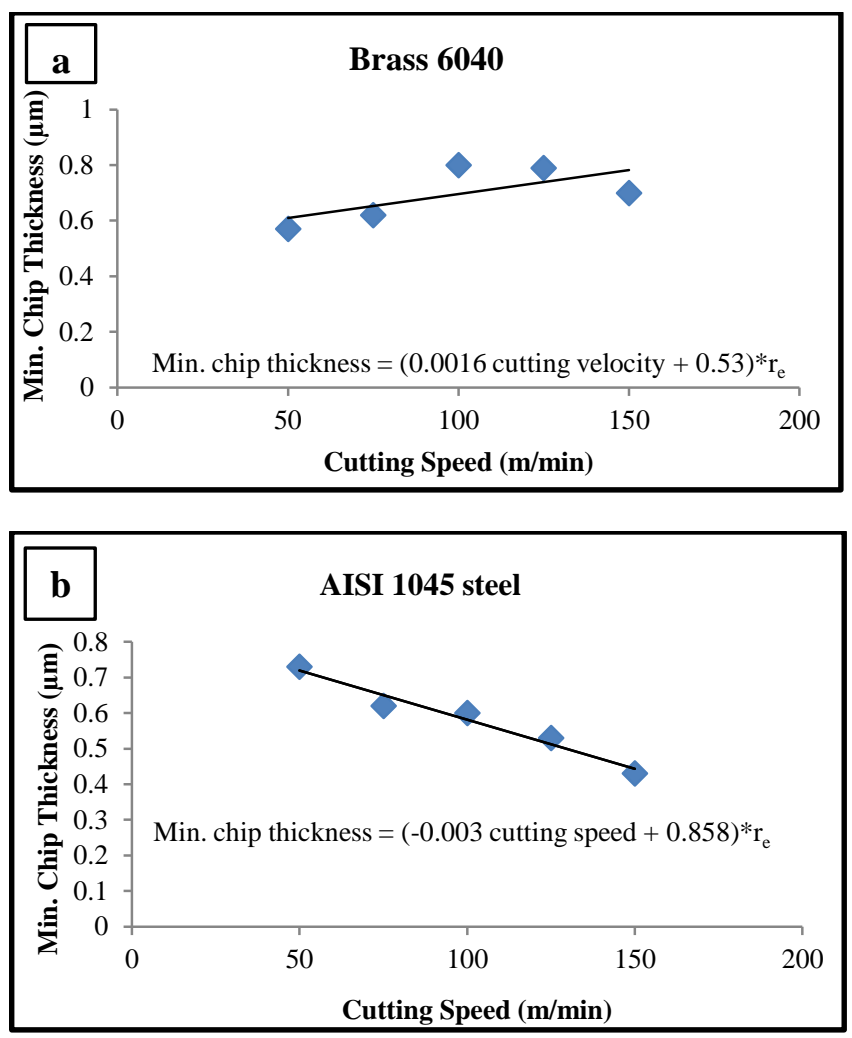

Fig. (4): Regression analysis between minimum chip thickness and cutting speed for (a) Brass 6040 and (b)AISI 1045 steel

Particularly, the relationship between minimum chip thickness and cutting speed for Brass 6040 and AISI 1045 steel is explained by Eq. (1) and Eq. (2), respectively

Min. chip thickness for Brass 6040
$=(0.0016 *$ cutting speed +0.53$) *$ edge radius

Min. chip thickness for AISI 1045 steel

$=(-0.003 *$ cutting speed +0.858$) *$ edge radius

Note that for simplicity linear trend was assumed for both regression models. These equations are incorporated into the surface generation model, previously proposed by the authors [12], of ultra-precision turning to illustrate the effect of cutting speed on surface roughness.

\section{SIMULATION AND OPTIMIZATION STUDY}

\subsection{Simulation of Surface Roughness}

Simulations trials of surface roughness obtained in ultraprecision turning have been conducted. The simulation was performed using the modified version of the formerly developed ultra-precision model [12], as shown in Fig. (5). Adapted model considered the effect of the kinematic parameters, applied feed and cutting speed, elastic recovery and minimum chip thickness and their associated uncertainty on two dual-phase materials, Brass 6040 and AISI 1045 steel. Due to the importance of cutting edge radius which plays dominant role in the surface generation process [9], the simulation trails were undertaken using cutting tools with nose radii of $200 \mu \mathrm{m}$ and $400 \mu \mathrm{m}$ with ranges of cutting edge radii, particularly from $5 \mu \mathrm{m}$ to 40 $\mu \mathrm{m}$ and feed rate varies between $5 \mu \mathrm{m}$ to $120 \mu \mathrm{m}$ with an increment of $5 \mu \mathrm{m}$.

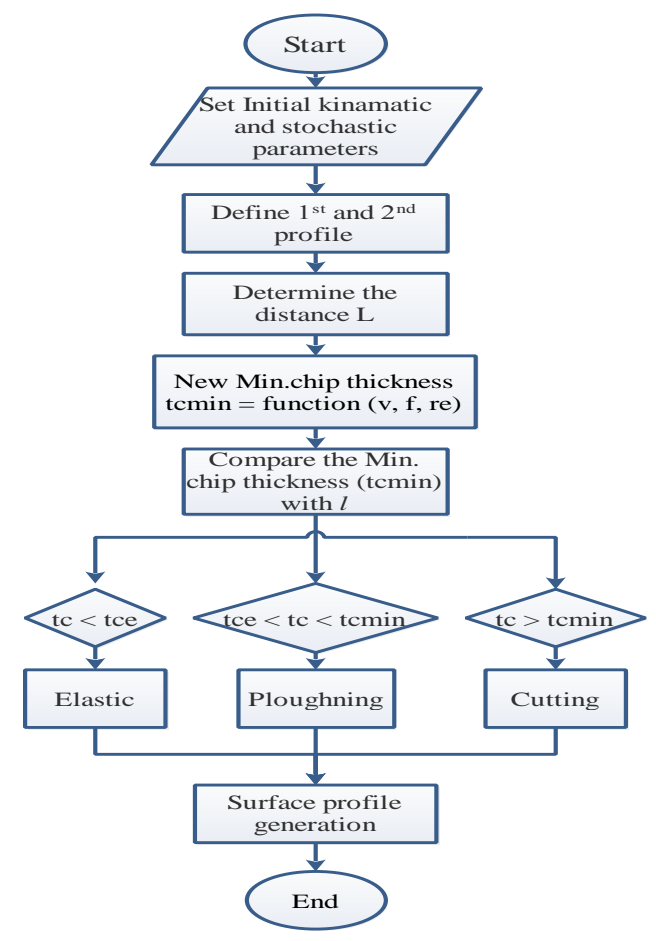

Fig. (5): Ultra-precision turning model [12] 


\subsection{Optimization of the comprehensive ultra- precision model}

The optimization of the surface roughness model detailed in ultra-precision turning was implemented. , The optimization was performed for the ultra-precision turning using two different optimization techniques; Sequential Quadratic Programming (SQP) and Genetic Algorithm (GA). Particularly, the optimization carried out to identify the optimum cutting conditions, cutting speed and feed rate when turning of two dual-phase materials, Brass 6040 and AISI 1045 steel using cutting tools with nose radius of $200 \mu \mathrm{m}$ and $400 \mu \mathrm{m}$ and cutting edge radius of $5 \mu \mathrm{m}, 20$ $\mu \mathrm{m}$, and $40 \mu \mathrm{m}$.

\subsubsection{Sequential Quadratic Programming (SQP)}

The optimum cutting conditions in the ultra-precision turning model can be obtained by using a special optimization tool box in MATLAB. The methodology of the minimization function, fmincon, function is a reliable tool to solve the minimum of a constrained non-linear objective function of several variables starting at user specified initial estimate. fmincon relies on (SQP) method with the active set optimization algorithm and contains a collection of algorithms that govern how a local minimum point is reached. First of all, it is important to define the objective function of ultra-precision turning model is minimize the surface roughness $R_{a}(x)$. The surface roughness $\mathrm{R}_{\mathrm{a}}(\mathrm{x})$ is a function of cutting speed $\left(\mathrm{x}_{1}\right)$ and feed $\left(x_{2}\right)$. Then, constraint considered includes the limitation of feed which is larger than cutting edge radius $\left(r_{e}\right)$. The procedure followed to undertake the (SQP) algorithm is as shown in Fig. (6).

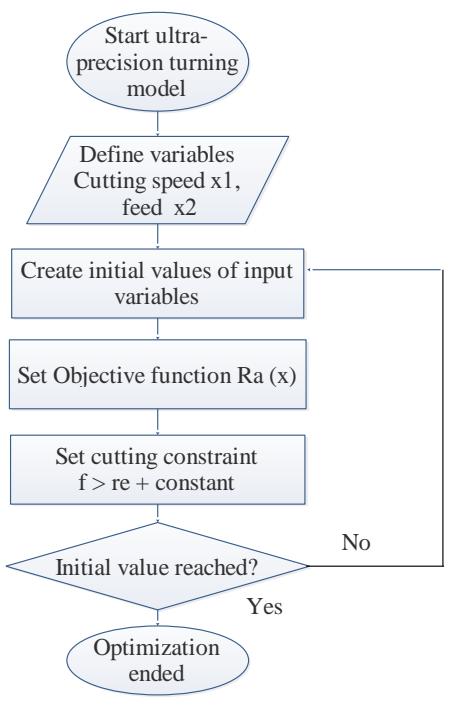

Fig. (6): Basic flow chart of SQP

Finally, minimizing the surface roughness $\left(\mathrm{R}_{\mathrm{a}}\right)$ can be obtained and values of cutting conditions.

\subsubsection{Genetic Algorithm (GA)}

Genetic algorithm (GA) is one of optimization algorithms based on the mechanics of natural selection and natural genetics, which are more robust and likely to locate a global optimum solution. The initial population consists of a set of randomly generated strings cutting speed $\left(\mathrm{x}_{1}\right)$ and feed $\left(\mathrm{x}_{2}\right)$. The objective of the present problem, fitness function, is to find the optimal cutting condition which gives the minimum surface roughness $\left(R_{a}\right)$. The objective function is calculated for each string in the population. The fitness values of each string are calculated and the expected count of each string for the next population is obtained. Then crossover and mutation process are applied on the model. This process is repeated for a specified number of generations. At the end of the last generation, the string corresponding to the minimum value is taken as the optimal surface roughness.

\section{RESULTS AND DISCUSSIONS}

\subsection{Simulation of the Effect of Cutting Speed on Surface Roughness}

\subsubsection{For Brass 6040}

The resultant surface roughness for Brass 6040 at the considered feed range and tools with nose radii of $200 \mu \mathrm{m}$ and $400 \mu \mathrm{m}$, respectively, is presented.

Figures (7-a), (7-b) and (7-c) show the simulation of surface roughness results of Brass 6040 using cutting tool with nose radius of $200 \mu \mathrm{m}$, considering the effect of cutting speed and feed at different cutting edge radii, particularly $5 \mu \mathrm{m}, 20 \mu \mathrm{m}$ and $40 \mu \mathrm{m}$, respectively.

The simulation results revealed that surface roughness is proportionally increased with the increase of feed until it reached the highest value of surface roughness. Then, the values of surface roughness gradually decreased with the increase of the applied feed where the minimum roughness was achieved. This showed the significant effect of the minimum chip thickness, especially when the values of applied feed was comparable to the cutting edge of the tool. With the increase of feed beyond the optimum point, the roughness increased again due to the influence of the kinematic parameters similar to those at macro-scale machining [13].

However, the cutting speed indirectly affects the resultant roughness by influencing the modified minimum chip thickness as explained in Eq. (1) that was incorporated into the proposed model. It is obvious that the obtainable minimum roughness is linearly proportional to the cutting speed.

For cutting tool with nose radius of $200 \mu \mathrm{m}$ and constant cutting edge radius of $5 \mu \mathrm{m}$, the minimum roughness obtained at feed of 30,35 , and $40 \mu \mathrm{m} /$ revolution for cutting speed of 50, 100, and $150 \mathrm{~m} /$ minute, respectively. Similarly, the minimum surface roughness at cutting edge radius $20 \mu \mathrm{m}$ occurred at feed 60,65 , and $70 \mu \mathrm{m} /$ revolution when cutting speed were 50,100 , and $150 \mathrm{~m} /$ minute, respectively. For cutting edge radius 40 
$\mu \mathrm{m}$, the minimum roughness obtained at feed 85,90 , and $95 \mu \mathrm{m} /$ revolution when cutting speed were 50, 100, and $150 \mathrm{~m} /$ minute, respectively.
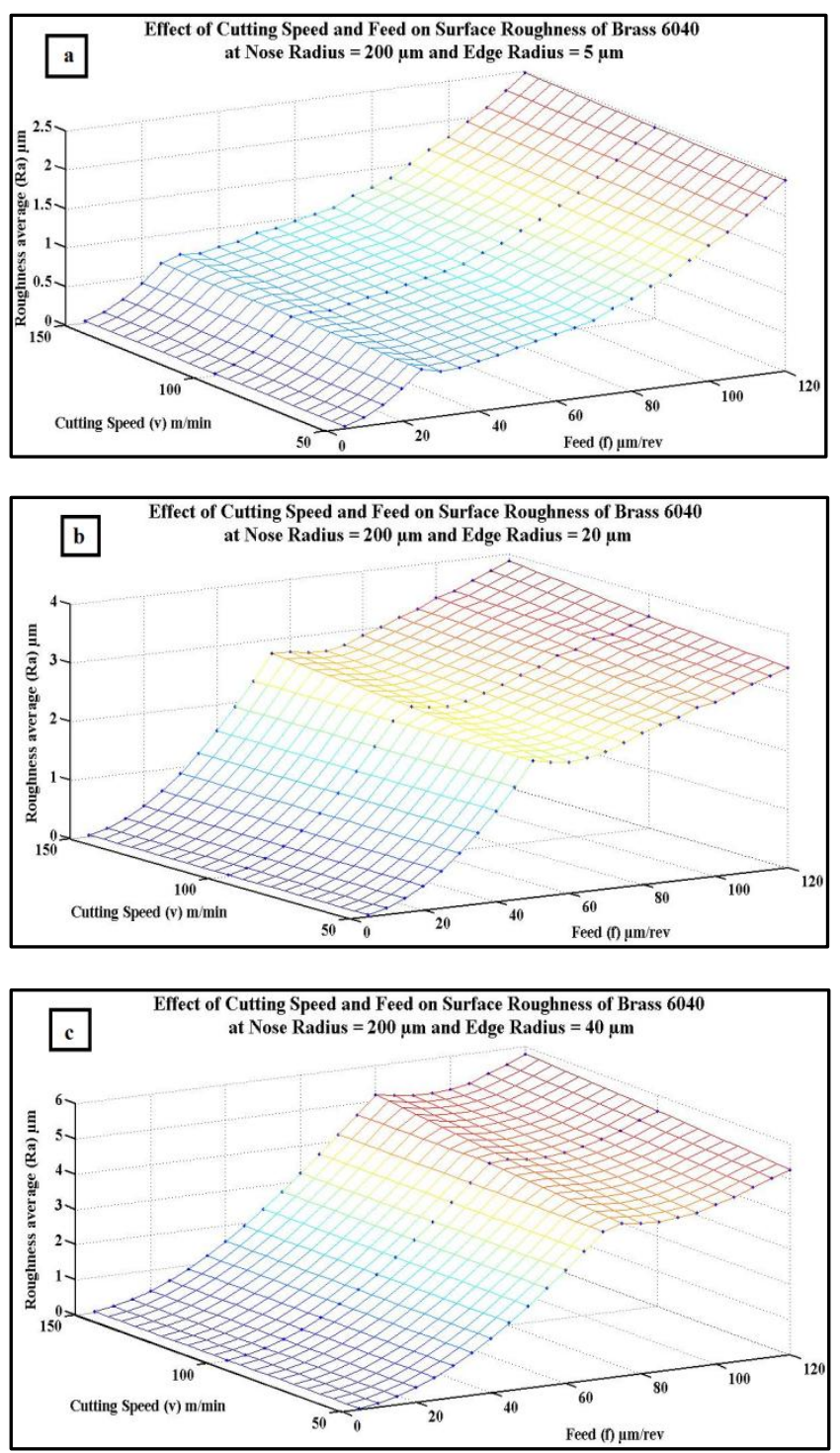

Fig. (7): Effect of cutting speed and feed on surface roughness of Brass 6040 at nose radius of $200 \mu \mathrm{m}$ and edge radius ( $\left.r_{e}\right)$ of (a) $5 \mu \mathrm{m}$, (b) (re) $20 \mu \mathrm{m}$ and (c) $40 \mu \mathrm{m}$

Comparing the simulation results obtained for Brass 6040 at different cutting edge radii, while the remaining conditions were kept constant, there is a clear evidence that cutting edge radius has significant effect on surface roughness. Particularly, the obtained minimum surface roughness value is proportionally increased with the increase of cutting edge radius.

In the case of Brass 6040 using cutting tool with a nose radius of $400 \mu \mathrm{m}$, the trend observed during simulation is relatively similar to those obtained when using cutting tool with nose radius $200 \mu \mathrm{m}$ as shown in Figures (8-a), (8-b) and (8-c). Also, the effect of cutting speed on minimum roughness value is similar to those obtained when using cutting tool with nose radius $200 \mu \mathrm{m}$.

For cutting tool with nose radius $400 \mu \mathrm{m}$ and constant cutting edge radius of $5 \mu \mathrm{m}$, the minimum roughness occurred at feed rates of 45,50 , and $55 \mu \mathrm{m} /$ revolution for cutting speed of 50,100 , and $150 \mathrm{~m} /$ minute, respectively. Similarly, the minimum roughness at cutting edge radius $20 \mu \mathrm{m}$ occurred at feed of 85,90 , and $95 \mu \mathrm{m} /$ revolution when cutting speed were 50,100 , and $150 \mathrm{~m} /$ minute, respectively. For cutting edge radius of $40 \mu \mathrm{m}$, the minimum roughness obtained at feed equaled 120, 130, and $135 \mu \mathrm{m} /$ revolution for cutting speed of 50,100 , and $150 \mathrm{~m} /$ minute, respectively.

Comparing the results obtained for brass 6040 at different nose radius, there is clear evidence that cutting speed, feed and cutting edge radius had dominant influence on the achievable surface roughness. This can be concluded as the results of minimum roughness obtained by cutting tools with nose radius of $400 \mu \mathrm{m}$ was higher than those resulted using tools with $200 \mu \mathrm{m}$ nose radius, under the same conditions.
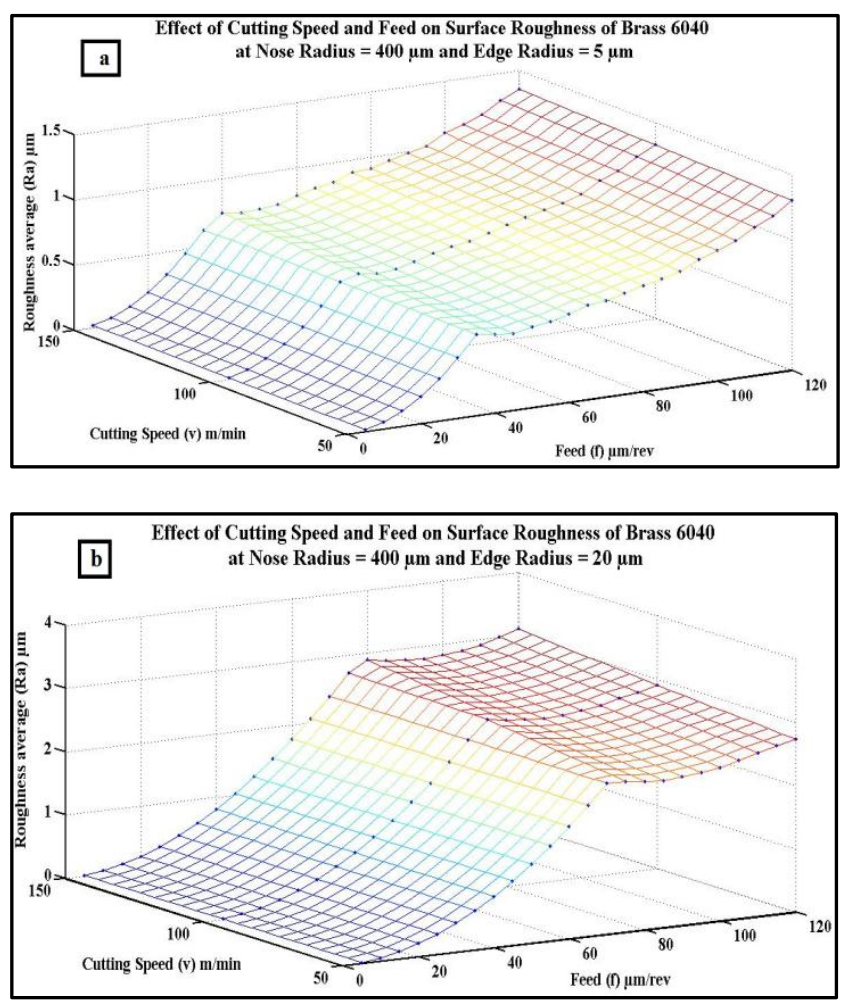


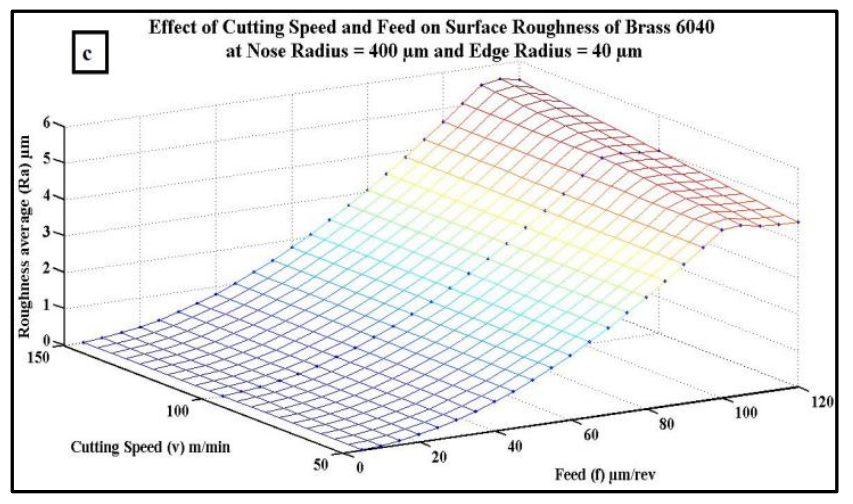

Fig. (8): Effect of cutting speed and feed on surface roughness of Brass 6040 of nose radius $400 \mu \mathrm{m}$ and edge radius (re) of (a) $5 \mu \mathrm{m}$, (b) (re) $20 \mu \mathrm{m}$ and (c) $40 \mu \mathrm{m}$

\subsubsection{For AISI 1045 Steel}

The simulation results for AISI 1045 steel samples over the considered ranges of cutting speed, feed range and the cutting tool geometry are presented in Figures (9-a), (9-b) and (9-c).

The simulation was undertaken using cutting tool with nose radius of $200 \mu \mathrm{m}$ and $400 \mu \mathrm{m}$, as shown in Figures (9-a), (9-b) and (9-c), respectively. Similarly to the case of Brass 6040, the achievable roughness demonstrated gradual increase with the increase of feed until it reached the highest value of roughness. The value of roughness steadily decreased with the increase of applied feed where the minimum surface roughness was achieved. With the increase of feed beyond the optimum point, the roughness increased again due to the effect of the kinematic parameters similar to those at conventional machining.

In particular, the cutting speed is indirectly influenced the resultant roughness by affecting the modified minimum chip thickness, as explained in Eq. (2) in the proposed model. The obtained minimum surface roughness is inversely proportional to the cutting speed. The higher cutting speed; the minimum roughness can be achieved.

For cutting tool with nose radius $200 \mu \mathrm{m}$ and constant cutting edge radius of $5 \mu \mathrm{m}$, the minimum roughness occurred at feed 35,30 , and $25 \mu \mathrm{m} /$ revolution for cutting speed 50,100, and $150 \mathrm{~m} /$ minute, respectively. Similarly, the minimum surface roughness at cutting edge radius 20 $\mu \mathrm{m}$ occurred at feed 65,60 , and $50 \mu \mathrm{m} /$ revolution when cutting speed were 50, 100, and $150 \mathrm{~m} /$ minute, respectively. However, for cutting edge radius $40 \mu \mathrm{m}$, the minimum roughness obtained at feed 95, 85, and $70 \mu \mathrm{m} /$ revolution when cutting speed were 50,100 , and $150 \mathrm{~m} /$ minute, respectively.

Comparing the simulation results obtained of AISI 1045 steel at different cutting edge radius, where the remaining conditions were kept constant, there is clear evidence that cutting edge radius have substantial effect on surface roughness. Especially, the obtained minimum roughness value proportionally increased with the increase of cutting edge radius.
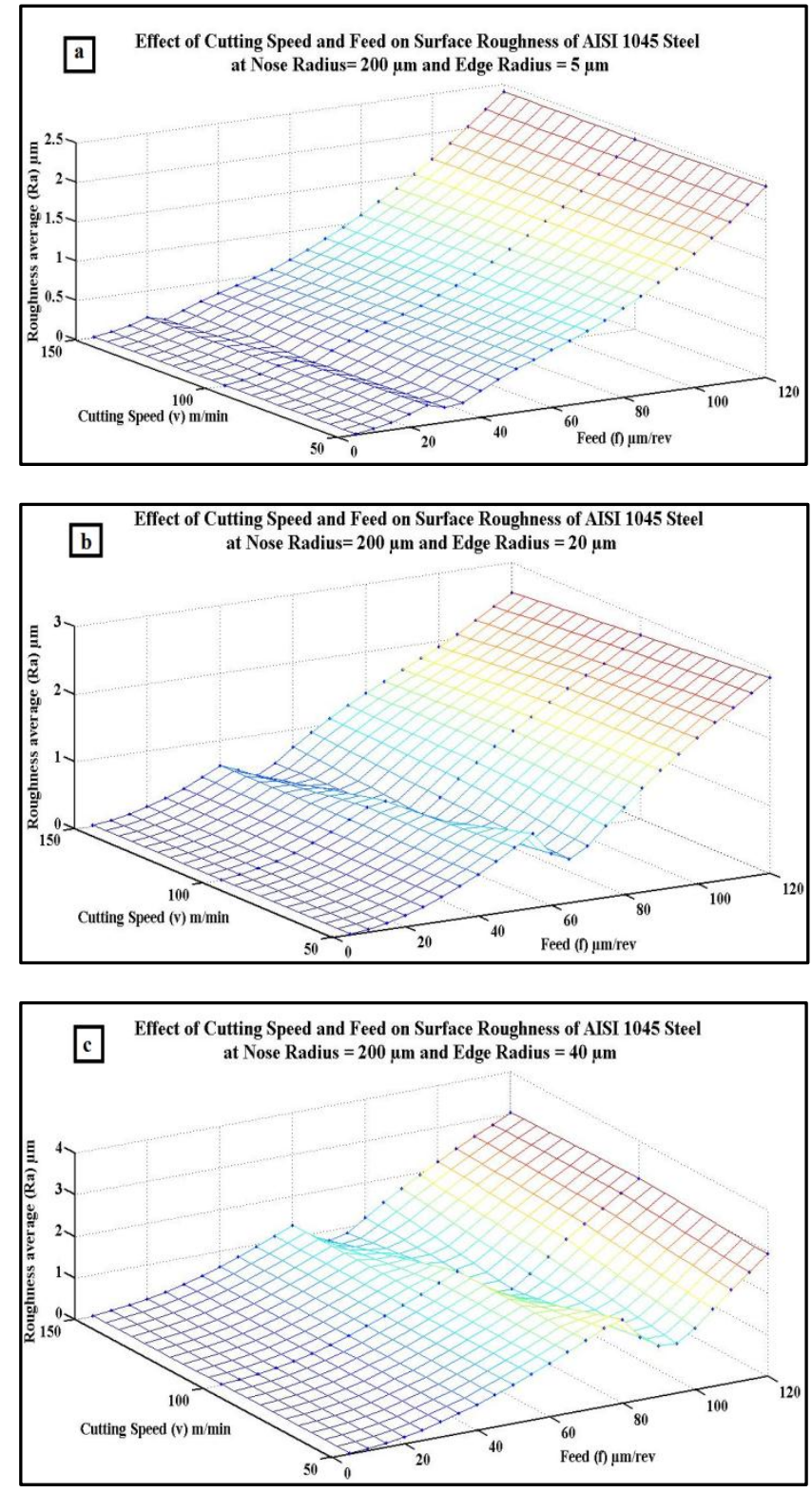

Fig. (9): Effect of cutting speed and feed on surface roughness of AISI $1045 \mathrm{steel}$ at nose radius of $200 \mu \mathrm{m}$ and different edge radius (re) of (a) $5 \mu \mathrm{m}$, (b) $20 \mu \mathrm{m}$ and (c) $40 \mu \mathrm{m}$

In case of AISI 1045 steel using cutting tool with a nose radius of $400 \mu \mathrm{m}$, the trend observed during simulation is relatively similar to those obtained when using cutting tool with nose radius $200 \mu \mathrm{m}$ as shown in Figures (10-a), (10b) and (10-c). Also, the effect of cutting speed on minimum roughness value is similar to those obtained when using cutting tool with nose radius $200 \mu \mathrm{m}$.

For cutting tool with nose radius $400 \mu \mathrm{m}$ and constant cutting edge radius of $5 \mu \mathrm{m}$, the minimum roughness occurred at feed rates 45,40 , and $35 \mu \mathrm{m} /$ revolution with cutting speed 50,100 , and $150 \mathrm{~m} /$ minute, respectively. Similarly, the minimum roughness at cutting edge radius $20 \mu \mathrm{m}$ occurred at feed 90,80 , and $70 \mu \mathrm{m} /$ revolution when 
cutting speed are 50,100 , and $150 \mathrm{~m} /$ minute, respectively. For cutting edge radius $40 \mu \mathrm{m}$, the minimum roughness obtained at feed 130,115 , and $100 \mu \mathrm{m} /$ revolution when cutting speed are 50,100 , and $150 \mathrm{~m} /$ minute, respectively.

Comparing the results obtained for AISI 1045 steel at different nose radius, there is clear evidence that cutting speed, feed and cutting edge radius have significant influence on the achievable surface roughness. This can be concluded as the results of minimum roughness obtained by cutting tools with nose radius of $200 \mu \mathrm{m}$ was higher than those resulted using tools with $400 \mu \mathrm{m}$ nose radius, under the same conditions.
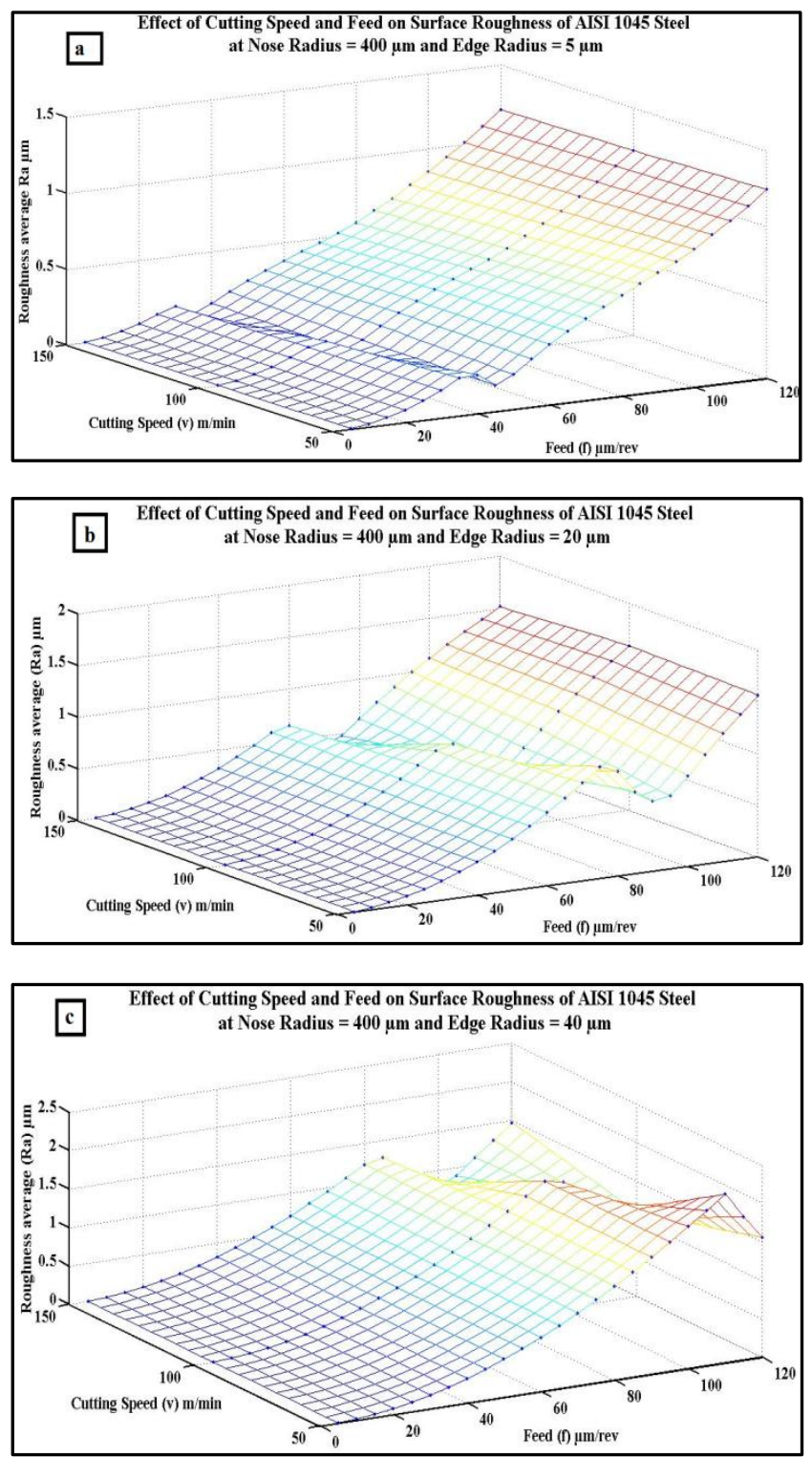

Fig. (10): Effect of cutting speed and feed on surface roughness of AISI 1045 steel at nose radius $400 \mu \mathrm{m}$ and different edge radius (re) (a) $5 \mu \mathrm{m}$, (b) $20 \mu \mathrm{m}$ and (c) $40 \mu \mathrm{m}$

\subsection{Optimization results}

Following are the results obtained by applying the optimization of roughness model and to identify the optimum cutting conditions. As previously stated, two optimization techniques were utilized; namely SQP and GA. In particular, the optimization trials were obtained at different cutting tool nose radii and at different levels of cutting edge radii as input parameters. For GA, the generation undertaken to find the fitness function illustrated in Fig. (11). the results of the optimum cutting conditions of the proposed model expressed in Table (2).

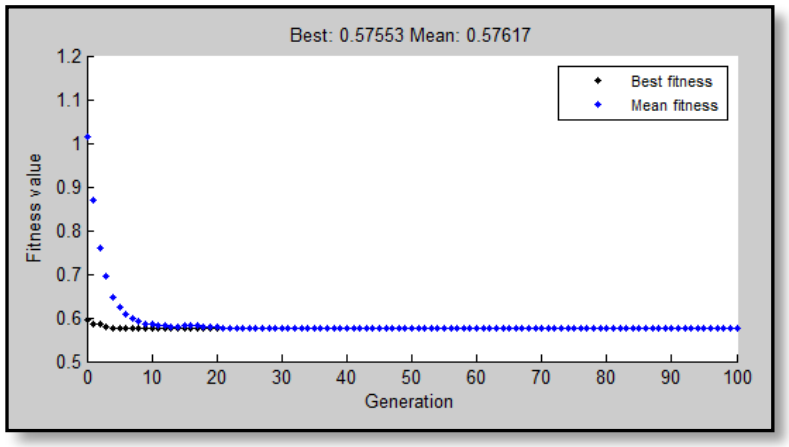

Fig. (11): Genetic algorithm fitness function vs. generation

Table (2): Optimum cutting condition for Brass 6040 and AISI 1045 steel

\begin{tabular}{|l|c|c|c|c|}
\hline $\mathrm{re}_{\mathrm{e}} 5 \mu \mathrm{m}$ & \multicolumn{4}{|c|}{ Brass 6040 } \\
\hline $\mathrm{tc}_{\min }$ & \multicolumn{4}{|c|}{$\left(0.0016^{*} \mathrm{v}+0.53\right) * \mathrm{re}$} \\
\hline $\mathrm{K}$ & \multicolumn{4}{|c|}{0.7975} \\
\hline $\mathrm{r}_{\mathrm{c}}(\mu \mathrm{m})$ & \multicolumn{2}{|c|}{200} & $\mathrm{c} 400$ \\
\hline Optimization Tech. & $\mathrm{SQP}$ & $\mathrm{GA}$ & $\mathrm{SQP}$ & $\mathrm{GA}$ \\
\hline Feed $(\mu \mathrm{m} / \mathrm{rev})$. & 25 & 30 & 25 & 25 \\
\hline Velocity $(\mathrm{m} / \mathrm{min})$ & 150 & 50 & 150 & 50 \\
\hline $\mathrm{R}_{\mathrm{a}}(\mu \mathrm{m})$ & 0.639 & 0.5755 & 0.3254 & 0.3254 \\
\hline
\end{tabular}

\begin{tabular}{|l|c|c|c|c|}
\hline $\mathrm{r}_{\mathrm{e}} 5 \mu \mathrm{m}$ & \multicolumn{4}{|c|}{ AISI 1045 Steel } \\
\hline $\mathrm{tc}_{\min }$ & \multicolumn{4}{|c|}{$(-0.003 * \mathrm{v}+0.858) * \mathrm{r}_{\mathrm{e}}$} \\
\hline $\mathrm{K}$ & \multicolumn{3}{|c|}{0.3} \\
\hline $\mathrm{r}_{\mathrm{c}}(\mu \mathrm{m})$ & \multicolumn{2}{|c|}{200} & \multicolumn{2}{c|}{400} \\
\hline Optimization Tech. & $\mathrm{SQP}$ & $\mathrm{GA}$ & $\mathrm{SQP}$ & $\mathrm{GA}$ \\
\hline Feed $(\mu \mathrm{m} / \mathrm{rev})$. & 25 & 25 & 33 & 35 \\
\hline Velocity $(\mathrm{m} / \mathrm{min})$ & 150 & 148.6 & 150 & 150 \\
\hline $\mathrm{R}_{\mathrm{a}}(\mu \mathrm{m})$ & 0.1024 & 0.1024 & 0.1162 & 0.1018 \\
\hline
\end{tabular}

The results show that there are an agreement between the optimum solutions obtained by SQP and GA. For Brass 6040, GA gave better results, especially the optimum surface roughness is lower than those identified by SQP when using cutting tool with nose radius of $200 \mu \mathrm{m}$. On the other hand, when using cutting tool with nose radius 
$400 \mu \mathrm{m}$ the optimum cutting conditions by both SQP and GA have the same values of roughness.

Similarly, the optimum cutting conditions, values of cutting speed and feed, for the minimum surface roughness of AISI 1045 steel were identical by SQP and GA when using cutting tool with nose radius of $200 \mu \mathrm{m}$. However, when using cutting tool with nose radius of $400 \mu \mathrm{m}$, the minimum surface roughness that was determined by GA and SQP were nearly close.

Knowing the trend of the proposed mode, from the simulation results, one can argue that, the predicted minimum surface roughness obtained by the simulation agreed well with those obtained by optimization techniques. Also, the results showed that results by the Genetic algorithm (GA) perfectly matched the minimum roughness observed in simulation results than those obtained by SQP.

In order to maximize the benefits of the proposed simulation and optimization study, the optimization ran for varying values of cutting edge radii to simulate the process performance at different level of tool wear. Table (3) and Table (4) illustrate the optimum cutting conditions at different cutting edge radii, particularly in additions to 5 $\mu \mathrm{m}$ edge radius too, cutting edge radii of $20 \mu \mathrm{m}$ and $40 \mu \mathrm{m}$ were also studied.

Table (3) and Table (4) show that minimum roughness obtained by GA is more accurate than the results achieved by SQP in case of cutting edge radius of $20 \mu \mathrm{m}$ and 40 $\mu \mathrm{m}$. In Table (3), for Brass 6040 the minimum surface roughness obtained by GA when using cutting tool with nose radius $200 \mu \mathrm{m}$ and $400 \mu \mathrm{m}$ are less than simulation results, which can be explained by the large increment, 5 $\mu \mathrm{m}$, that was used to carry out the simulation. Conversely, the minimum roughness obtained by SQP gave results larger than those obtained by simulation study. As a result, GA has shown more potential to optimize the roughness model accurately than the SQP.

For AISI 1045 steel, the results obtained by GA and SQP at cutting edge radii of $20 \mu \mathrm{m}$ and $40 \mu \mathrm{m}$ were found to be very close to those obtained by simulation. However, the minimum surface roughness and its associated cutting conditions obtained by GA were found optima than the results of the SQP. So, in general it is not so difficult to sum up that GA resulted in better results in terms of the minimum roughness than the SQP.

Table (3): Optimum cutting condition for Brass 6040 and AISI 1045 steel at edge radius $20 \mu \mathrm{m}$

\begin{tabular}{|c|c|c|c|c|}
\hline $\mathrm{r}_{\mathrm{e}}=20 \mu \mathrm{m}$ & \multicolumn{4}{|c|}{ Brass 6040} \\
\hline $\mathrm{tc}_{\min }$ & \multicolumn{4}{|c|}{$(0.0016 * \mathrm{v}+0.53) * \mathrm{re}$} \\
\hline $\bar{K}$ & \multicolumn{4}{|c|}{0.7975} \\
\hline$\overline{r_{c}(\mu \mathrm{m})}$ & \multicolumn{2}{|c|}{200} & \multicolumn{2}{|c|}{400} \\
\hline Optimization Tech. & SQP & GA & SQP & GA \\
\hline Feed $(\mu \mathrm{m} / \mathrm{rev})$. & 100 & 40 & 100 & 40 \\
\hline Velocity(m/min) & 150 & 50 & 150 & 50 \\
\hline
\end{tabular}

\begin{tabular}{|l|l|l|l|l|}
\hline $\mathrm{R}_{\mathrm{a}}(\mu \mathrm{m})$ & 3.4008 & 1.5531 & 2.8289 & 0.8133 \\
\hline
\end{tabular}

\begin{tabular}{|c|c|c|c|c|}
\hline$r_{e}=20 \mu \mathrm{m}$ & \multicolumn{4}{|c|}{ AISI 1045 Steel } \\
\hline$t c_{\min }$ & \multicolumn{4}{|c|}{$\left(-0.003 *^{*} \mathrm{v}+0.858\right) * \mathrm{re}$} \\
\hline $\mathrm{K}$ & \multicolumn{4}{|c|}{0.3} \\
\hline$\overline{r_{c}(\mu \mathrm{m})}$ & \multicolumn{2}{|r|}{200} & \multicolumn{2}{|c|}{400} \\
\hline Optimization Tech. & SQP & GA & SQP & GA \\
\hline Feed $(\mu \mathrm{m} / \mathrm{rev})$. & 50 & 49.58 & 41 & 41 \\
\hline Velocity (m/min) & 150 & 150 & 150 & 137.5 \\
\hline $\mathrm{R}_{\mathrm{a}}(\mu \mathrm{m})$ & 0.3935 & 0.3933 & 0.3193 & 0.3193 \\
\hline
\end{tabular}

Table (4): Optimum cutting condition for Brass 6040 and AISI 1045 steel at edge radius $40 \mu \mathrm{m}$

\begin{tabular}{|l|c|c|c|c|}
\hline $\mathrm{r}_{\mathrm{e}}=40 \mu \mathrm{m}$ & \multicolumn{4}{|c|}{ Brass 6040 } \\
\hline $\mathrm{tc}_{\min }$ & \multicolumn{4}{|c|}{$0.0016^{*} \mathrm{v}+0.3^{*} \mathrm{re}$} \\
\hline $\mathrm{K}$ & \multicolumn{3}{|c|}{200} & \\
\hline $\mathrm{r}_{\mathrm{c}}(\mu \mathrm{m})$ & $\mathrm{GA}$ & $\mathrm{SQP}$ & $\mathrm{GA}$ \\
\hline Optimization Tech. & $\mathrm{SQP}$ & $\mathrm{GA}$ & 600 \\
\hline Feed $(\mu \mathrm{m} / \mathrm{rev})$. & 100 & 60 & 60 & 60 \\
\hline Velocity $(\mathrm{m} / \mathrm{min})$ & 150 & 50 & 150 & 50 \\
\hline $\mathrm{R}_{\mathrm{a}}(\mu \mathrm{m})$ & 5.0559 & 3.2232 & 1.7802 & 1.7802 \\
\hline
\end{tabular}

\begin{tabular}{|l|c|c|c|c|}
\hline$r_{e}=40 \mu \mathrm{m}$ & \multicolumn{4}{|c|}{ AISI 1045 Steel } \\
\hline $\mathrm{tc}_{\min }$ & \multicolumn{4}{|c|}{$\left.0.003^{*} \mathrm{v}+0.858\right){ }^{*} \mathrm{re}$} \\
\hline $\mathrm{K}$ & \multicolumn{3}{|c|}{200} & \\
\hline $\mathrm{r}_{\mathrm{c}}(\mu \mathrm{m})$ & $\mathrm{SQP}$ & $\mathrm{GA}$ & $\mathrm{SQP}$ & $\mathrm{GA}$ \\
\hline Optimization Tech. & 69 & 70 & 100 & 61 \\
\hline Feed $(\mu \mathrm{m} / \mathrm{rev})$. & 150 & 150 & 150 & 137.2 \\
\hline Velocity $(\mathrm{m} / \mathrm{min})$ & 0.7627 & 0.7443 & 0.7969 & 0.7025 \\
\hline $\mathrm{R}_{\mathrm{a}}(\mu \mathrm{m})$ & & &
\end{tabular}

\section{CONCLUSIONS}

This paper has reported on the simulation and optimization of the surface generation model previously developed to predict surface generation during ultraprecision turning of dual-phase materials.

The simulation judged the effects of the kinematic factors; feed rate, cutting speed, and the cutting tool geometry in addition to the material characteristics in term of minimum chip thickness and elastic recovery. In particular, the simulation conducted for on two different dual-phase materials, Brass 6040 and medium carbon steel AISI 1045, under a range of processing parameters. All simulation trails were carried out using cutting tools with nose radius of $200 \mu \mathrm{m}$ and $400 \mu \mathrm{m}$ with different levels of cutting edge radii started from $5 \mu \mathrm{m}$ to $40 \mu \mathrm{m}$. 
The feed ranges were $5 \mu \mathrm{m}$ to $120 \mu \mathrm{m}$ with an increment of $5 \mu \mathrm{m}$. The results of simulation paid great deal of attention to the effect of cutting speed, feed, and tool geometry, especially cutting edge radius and nose radius, on the attainable surface roughness. After that, two optimization techniques, GA and SQP, were utilized to identify the optimal cutting conditions for the minimum surface roughness. The following specific conclusions were drawn;

- The simulation study conducted for Brass 6040 at different nose radii showed clear evidence that cutting edge radius and nose radius have major effect on the surface roughness results. It can be seen clearly that feed used to obtain the minimum surface roughness increased by approximately $30 \%$ to $50 \%$ when using different cutting edge radii and different nose radii. Similarly to Brass 6040, the minimum surface roughness obtained for AISI 1045 steel altered by approximately $40 \%$ over the range of different cutting edge radii and nose radii examined.

- The simulation results of minimum surface roughness value of AISI 1045 steel was obtained at lower value of feed than those obtained for Brass 6040. This can be explained by the effect of uncertainty of minimum chip thickness, which is lower in AISI 1045 steel than Brass 6040 .

- The results of this research have pointed out the need for the special attention to be paid to the effect of cutting speed, feed and cutting edge radii on surface generation.

- In a clear way, the simulation obtained of Brass 6040 showed that the minimum surface roughness proportionally increased with the increase of cutting speed. However, for AISI 1045 steel the simulation results revealed that the minimum roughness is inversely proportional to the cutting speed.

- One can argue that, the predicted minimum surface roughness obtained by the simulation agreed well with those obtained by optimization techniques. Also, the results showed that genetic algorithm (GA) perfectly matched the simulation results and had better performance than the SQP technique.

\section{ACKNOWLEDGMENT}

The authors wish to thank the Suez Canal Authority for providing technical support to the authors to fulfill this research endeavor. The authors gratefully acknowledge the support of Eng. Ali Abdel Aziz from the Suez Canal Authority workshop for his support in conducting the machining trials. Also, the authors gratefully acknowledge the support of Eng. Mohamed A. Negm for his support in conducting the programming trials.

\section{REFERENCES}

[1] Tao W., 2012, "Tooling Performance in Micro Milling: Modelling, Simulation and Experimental Study," PhD thesis, School of Engineering and Design, Brunel University

[2] Liu, X., Devore, R.E, Kapoor, S.G. 2006, “An analytical model for the prediction of minimum chip thickness in micromachining," ASME J. of Manufacturing Science and Engineering, 128, pp. $474-481$

[3] Mukherjee, I., Kumar, R.P., 2006,"A review of optimization techniques in metal cutting processes," Computers \& Industrial Engineering, 50, 15-34

[4] Shamara, R., Fjalestad, K., and Glemmestad, B., 2012,"Optimization of Lift Gas Allocation in Gas Lifted Oil Field as Non-Linear Optimization Problem," Modeling Identification and Control, 33, No. 1, pp. 13-25

[5] Elkaseer, A.M., Dimov, S.S., Minev, R. and Scholz, S., 2012, "Simulation-Based Study of the $\mu$-End milling process," Proceedings of the $7^{\text {th }}$ ICOMM, March 11-14, pp. 485-492, Illinois, USA

[6] Bhaskara Reddy, S.V., Shunmugam, M.S., Narendran, T.T., 1998," Optimal sub-division of the depth of cut to achieve minimum production cost in multi-pass turning using a genetic algorithm," Journal of Materials Processing Technology, 79, pp.101-108

[7] Wang, X., Da, Z.J., EDS, Balaji, A.K., and Jawahir, I.S., 2007," Performance-Based Predictive Models and Optimization Methods for Turning Operations and Applications: Part 3-Optimum Cutting Conditions and Selection of Cutting Tools," Journal of Manufacturing Process, 9, pp. 61-74

[8] Addona, D.M., Teti, R., 2013, "Genetic algorithmbased optimization of cutting parameters in turning processes," Forty Sixth CIRP Conference on Manufacturing Systems 2013, Procedia CIRP, 7, pp. $323-328$

[9] Liu, X., Devor, R.E., and Kapoor, S.G., 2007, "Model-based analysis of the surface generation in microendmilling-Part II: Experimental Validation and Analysis," ASME J. Manuf. Sci. Eng., 129, pp. 461-469 
[10] Özel, T., Liu, X. and Dhanorker, A., "Modelling and Simulation of Micro-Milling Process," 4th International Conference and Exhibition on Design and Production of Machines and Dies/Molds, 21-23 June 2007, Cesme, Turkey.

[11] Tamang, S.K. and Chandrasekaran, M., 2015," Modeling and optimization of parameters for minimizing surface roughness and tool wear in turning $\mathrm{Al} / \mathrm{SiCp} \mathrm{MMC}$, using conventional and soft computing techniques, " Advances in Production Engineering \& Management, 10, pp.59-72

[12] Elsanabary S., Elkaseer A., Abd-Rabbo S., AbdElsalam M., Abdou S. "Surface Generation in Ultra-Precision Turning Considering Process Uncertainty: Modeling and Experimental Validation," 17th International Conference on AMME , Paper submitted and the conference to be held on April 19-22, 2016

[13] Vogler, M., Kapoor, S. and Devor, R., 2004, "On the modeling and analysis of machining performance in micro end milling, Part 1: Surface generation," ASME J. of Manufacturing Science and Engineering, 126, pp. 685-694 